\title{
IMPLEMENTAÇÃO DE GESTÃO POR PROCESSOS EM UMA AUTARQUIA MUNICIPAL
}

\author{
PROCESS MANAGEMENT IMPLEMENTATION IN A MUNICIPAL AUTHORITY
}

\author{
Aldri Stefani Mosele Gomes de Souza \\ Bacharel em Administração pela Universidade Feevale. \\ Servidora pública \\ 0171790@ feevale.br \\ Dusan Schreiber \\ Doutor em Administração de Empresas pela UFRGS. \\ Professor e Pesquisador na Universidade Feevale, Novo Hamburgo, Rio Grande do Sul - Brasil. \\ dusan@feeval.br \\ Vanessa Theis \\ Doutora em Qualidade Ambiental pela Universidade Feevale. \\ Pesquisadora na Universidade Feevale, Novo Hamburgo, Rio Grande do Sul - Brasil. \\ Universidade Feevale. \\ vanessat@feevale.br
}

Resumo: A Gestão por Processos pode ser definida como ferramenta de controle e transformação dos processos das organizações para a otimização de recursos e minimização de perdas. Considerando-se que o cidadão brasileiro tem exigido, cada vez mais, mudanças para modernizar a administração pública, para que a mesma consiga prestar serviços de alto nível de qualidade e com custos reduzidos, o objetivo desta pesquisa foi o de evidenciar as tarefas que integram o setor de conferência em uma Autarquia de previdência pública do município de Campo Bom, no estado do Rio Grande do Sul, com o objetivo de analisar a possibilidade da implementação da gestão por processos. Em termos metodológicos o estudo possui abordagem qualitativa, objetivo exploratório e descritivo e como estratégia de pesquisa um estudo de caso único, sendo os dados obtidos por meio de entrevistas semiestruturadas, observação participante e pesquisa documental. Os resultados evidenciaram o volume de trabalho e sua complexidade e a necessidade de mudança na estrutura do setor de conferência para viabilizar a implementação da gestão por processos. A principal contribuição do estudo, diz respeito às características práticas e gerenciais, visto que, com o mapeamento dos processos, será confirmada a viabilidade de adoção da gestão por processos no setor analisado, bem como os potenciais benefícios para os servidores envolvidos, acarretando redução de ocorrência de erros e retrabalho, bem como maior agilidade na execução de tarefas.

Palavras-chave: Processos. Gestão por processos. Administração pública.

Abstract: Process Management can be defined as a tool for controlling and transforming organizations' processes to optimize resources and minimize losses. Considering that the Brazilian citizen has increasingly demanded changes to modernize the public administration, so that it can provide services of a high level of quality and with reduced costs, the objective of this article was to highlight the tasks of the conference sector in an Autarchy of public pension in the municipality of Campo Bom, in the state of Rio Grande do Sul, to analyze the possibility of implementing process management. In methodological terms the study has a qualitative approach, exploratory and descriptive objective and as a research strategy a single case study. The data being obtained through semi-structured interviews, participant observation and documentary research. The results showed the volume of work and its complexity and the need to change the structure of the conference sector to enable the implementation of management by processes. The main contribution of the study concerns the practical and managerial characteristics, since, with the mapping of the processes, the feasibility of adopting management by processes in the analyzed sector will be confirmed, as well as the potential benefits for the servers involved, resulting in a reduction of errors and rework, as well as greater agility in the execution of tasks.

Keywords: Processes. Process management. Public administration.

Cite como

American Psychological Association (APA)

Souza, A. S. M. G., Schreiber, D., \& Theis, V. (2021, jan./jun.). Implementação de gestão por processos em uma autarquia

Municipal. Revista Inovação, Projetos e Tecnologias - IPTEC, São Paulo, 9(1), 1-16. https://doi.org/10.5585/iptec.v9i1.17302. 


\section{Introdução}

O cenário atual da administração pública brasileira sofreu diversas modificações desde a promulgação do texto constitucional em 1988, com diferentes níveis de desenvolvimento entre as áreas da administração pública brasileira, tanto na esfera federal, estadual, como municipal. Não obstante, a máquina pública é ainda percebida, como burocrática e lenta, mas diversos são os fatores que colaboram para uma mudança de paradigma (Gespública, 2010).

Nesta perspectiva, a busca por soluções eficazes levou as instituições públicas a reverem suas estruturas organizacionais, de modo a não mais agrupá-las partir das atividades de suas áreas funcionais, mas sob a perspectiva dos contribuintes. Assim, contata-se que ocorreu a alteração do foco administrativo, do fluxo de trabalho de áreas funcionais para processos de negócio da organização (de Sordi, 2017). Ademais, a gestão por processos representa uma nova proposta de gerenciamento, que pode assegurar a execução eficaz dos recursos disponíveis (Harmon, 2019).

Neste contexto, o presente estudo, realizado por meio de estudo de caso único, visa evidenciar as tarefas que integram o setor de conferência em uma Autarquia de previdência pública do município de Campo Bom, no estado do Rio Grande do Sul, com o objetivo de analisar a possibilidade da implementação da gestão por processos. Cumpre destacar que, no referido setor existe grande complexidade no conteúdo do trabalho exercido, além de ocorrer diversos eventos que ocasionam atrasos e distração dos servidores. Os processos são burocráticos, manuais e não possuem fluxograma das atividades, por vezes é confuso identificar quais etapas estão sendo realizadas, quais já foram e quais ainda não foram realizadas

Após esta introdução, o artigo apresenta a seguinte estrutura: a contextualização da gestão por processos, com destaque para o Business Process Management. A seguir, são elencados os procedimentos metodológicos, e, por fim, expõe-se a análise dos resultados. Após a descrição e apresentação do corpus pesquisado, estão descritas as considerações finais em relação ao objetivo, e destacando as limitações e sugestões para investigações futuras.

\section{Gestão por processos}

Em termos conceituais, um processo é definido por Slack e Brandon-Jones (2018), como um grupo de tarefas que têm interligação lógica, baseadas no uso de recursos da empresa para gerar determinados resultados consistentes com seus objetivos. Além disto, refere-se a técnica pela qual é possível avaliar, analisar e melhorar o desempenho dos processos que impactam positivamente a satisfação dos clientes (Klun \& Trkman, 2018).

Para Gonçalves (2000), processo é qualquer atividade ou conjunto de atividades que toma um input, adiciona valor a ele e fornece um output a um cliente específico. Jesus e 
Macieira (2014) esclarecem que a gestão por meio de processos pressupõe alterações organizacionais maiores em toda a forma de pensar e gerir um negócio, e que está implícita uma busca gradativa por maior colaboração, com ênfase na responsabilidade transversal e na organização do trabalho de maneira diferente.

Assim, os processos devem ser aplicados em estruturas organizacionais que interajam entre si, utilizando centros de competência e equipes multidisciplinares, possibilitando o conhecimento de forma holística (Barbará, 2008). Hammer (2001) ressalta que a criação de um processo estruturado faz com que as empresas se tornem menos dependentes de pequenos grupos de pessoas, visto que as empresas que possuem essa dependência, podem enfrentar situações adversas quando os colaboradores deixam a organização ou são transferidos de setor ou unidades.

Gonçalves (2000) aponta que dependendo da complexidade do processo este é dividido em subprocessos. Estes, por sua vez, são divisões do macroprocesso com objetivos específicos, organizado seguindo linhas funcionais. Os subprocessos recebem entradas e geram suas saídas em um único departamento e podem ser divididos nas diversas atividades que os compõem, e em um nível mais detalhado em tarefas. $\mathrm{O}$ autor destaca ainda que, quando acontece uma mudança, é inevitável que ocorra desconforto nos elementos envolvidos, visto que a gestão por processos traz desconforto nos colaboradores, por atribuir responsabilidade aos donos dos processos.

Sendo assim, os macroprocessos são processos básicos e fundamentais da organização, que a descrevem de forma geral e podem ser constituídos de microprocessos alocados pelos departamentos funcionais (Wagne, 2020). E, devem ser eficazes, eficientes, adaptáveis, mensuráveis, controláveis e formalizados. Sucintamente, os macroprocessos possuem processos; os processos possuem subprocessos, os quais possuem atividades. Por fim, as atividades possuem tarefas e assim por diante.

Para realizar a gestão por processos, torna-se necessário investigar algumas variáveis. A saber: a missão da empresa, os processos críticos de negócio que afetam os clientes, os recursos necessários para gerar os produtos, o que de essencial a organização oferece para os clientes e, como gerenciar o fluxo de informação, trabalho ou atividades e produtos, visando satisfazer os clientes (Barbará, 2008).

Gyory, Cagan e Kotovsky (2019) elencam as etapas presentes na gestão por processos, sendo elas, mapeamento, modelagem, oportunidade de melhoria, implantação/padronização e monitoramento. O mapeamento é a coleta de dados sobre os processos, envolve entrevistas com todos os envolvidos. Modelagem é o desenho do fluxo dos processos, a etapa oportunidade de melhoria, é consequência das 
duas etapas anteriores, onde também se verifica gargalos. Implantação/ padronização é onde se coloca tudo no papel, descrevendo como o processo deve ser executado. Por último, o monitoramento, que, como o próprio nome diz, monitora o alcance dos resultados esperados.

Cumpre destacar que o suporte no contexto de processos é indispensável, com destaque para os sistemas de automatização da gestão de processos. No tocante a este ponto, Pavani e Scucuglia (2011), sinalizam que os processos automatizados provêm maior eficiência do que àqueles dependentes de interações humanas. Dentre estas ferramentas, destaca-se as baseadas no conceito de Business Process Management (BPM), que se originou a partir de conceitos e tecnologias das áreas de negócios e tecnologia.

Os autores Brocke e Rosemann (2013), descrevem que, por meio de $B P M$, uma organização pode criar processos de alto desempenho, com custos mais baixos, maior velocidade, maior acurácia, melhor uso de ativos e maior flexibilidade. Chang (2016), corrobora que são atividades relacionadas ao BPM enxergar as pessoas e suas funções, mapear todos os processos de uma empresa, estabelecer o fluxo de trabalho, acompanhar e medir suas rotinas, corrigir e melhorar o rendimento do negócio como um todo.

Pavani e Scucuglia (2011), descrevem que o BPM foca na agregação de valor interfuncional, em que os interesses do processo se sobrepujam aos interesses departamentais. Araujo e Magdaleno (2015), reiteram que o BPM é uma abordagem sistemática para lidar com os processos de negócio, para alcançar resultados consistentes e alinhados com os objetivos estratégicos da organização. Sobre as ferramentas que dizem respeito ao BPM, Contador et al. (2005) apontam que os softwares utilizados na operacionalização e gerenciamento do processo resultam na facilidade para obtenção, distribuição e análise dos dados.

Os autores Baldam, Valle e Rozenfeld (2014) elencam que, tradicionalmente as empresas possuem uma visão focada nas funções que são exercidas por seus funcionários, essa perspectiva conduz a uma gestão hierárquica, rígida, departamental e vertical. Os autores Pavani e Scucuglia (2011), complementam que para a implementação da estrutura organizacional, baseada na gestão por processos, é necessário que a cultura da organização esteja aberta e adepta às principais quebras de paradigmas necessários para introduzir este novo conceito de organização do trabalho.

A gestão por processos, encontra consonância na transição para o modelo gerencial da administração pública, vivenciado no Brasil desde os anos 1990 e acentuado pela publicação do Decreto $\mathrm{n}^{\mathrm{o}}$ 5.378, de 23 de fevereiro de 2005, que institui o Programa Nacional de Gestão Pública e Desburocratização, tendo como um de seus objetivos promover a eficiência e eficácia, por meio de melhor aproveitamento dos recursos, relativamente aos resultados da ação pública (Gespública, 2016). Ferreira et al. (2014) elucidam que a gestão por processos é, portanto, um modelo adequado à gestão pública empreendedora, que adota princípios de gestão de negócios como atendimento ao cidadão como cliente, proatividade, iniciativa e autonomia gerencial, bem como controle por objetivos e metas. 
Gulledge e Sommer (2002) reiteram que o principal benefício da gestão por processos na esfera pública, é o aumento de eficiência e eficácia que pode ser alcançado por meio da reestruturação da organização por processos transfuncionais. Ainda, a gestão por processos abre portas para abordagens criativas e inovadoras visando melhorar a performance organizacional. Outra vantagem da implantação de gestão por processos é a promoção da integração entre a estrutura interna e sistemas de informação orientados por processos.

Para Biazzi e Muscat (2007), os modelos de análise e aperfeiçoamento de processos, em geral, são oriundos das organizações privadas. Contudo, em inclinação à administração pública, essa temática também passou a preocupar o setor público, que sofre pressões para melhorar seu desempenho e demonstrar maior transparência e avaliação de resultados. Contudo, existem características específicas do setor público que exercem influência sobre programas de melhoria ou qualquer programa de mudança, tais como: hierarquias rígidas; cultura do setor; estabilidade dos funcionários; mudanças de gestão periódica, muitas vezes enfatizando adaptações organizacionais de curto prazo.

Neste sentido, Bergue (2010) corrobora que a atuação das pessoas no ambiente organizacional ocorre segundo procedimentos de trabalho de caráter relativamente estável, ou seja, conforme uma sucessão de atividades que consome recursos e gera um resultado pretendido, marcado por um sensível grau de continuidade. Assim, a compreensão dos métodos e processos de trabalho deve constituir um dos objetivos centrais de análise do gestor, com vistas à melhoria do desempenho das pessoas, com reflexos diretos no resultado da ação do Poder Público.

\section{Método}

A presente pesquisa, realizada por meio de estudo de caso único, visa evidenciar as tarefas que integram o setor de conferência em uma Autarquia de previdência pública do município de Campo Bom, no estado do Rio Grande do Sul, com o objetivo de analisar a possibilidade da implementação da gestão por processos. A entidade foi instituída por lei própria, no ano de 1993, com personalidade jurídica de natureza autárquica, constituído por autonomia administrativa, patrimonial e financeira. Tem por objetivo a realização das operações de seguridade social dos servidores públicos e seus dependentes, no campo previdenciário e assistencial. A Figura 1 apresenta a organização da entidade, em todos seus níveis hierárquicos. 
Figura 1 - Organograma da Autarquia

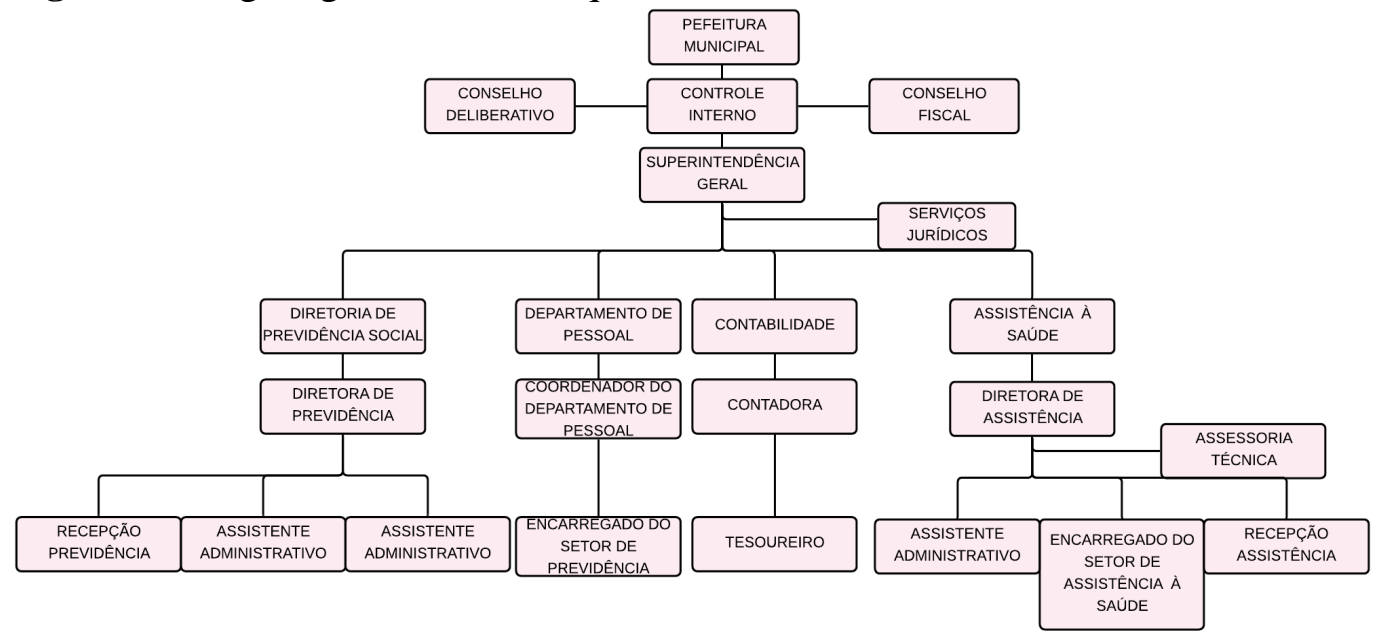

Fonte: Elaborado pelos autores.

A entidade é regida pelo conselho deliberativo, diretoria executiva e o conselho fiscal. Ao conselho deliberativo compete formular as políticas e diretrizes, fixar as propriedades e elaborar planos, programas e ação nas áreas de seguridade social inerentes aos objetivos e fins do Instituto. Além disso, cabe também, deliberar sobre a conveniência e oportunidade quanto ao desenvolvimento, incremento e ampliação das ações afetadas às áreas de seguridade social inseridas no âmbito de atuação da entidade, aprovar as propostas orçamentárias e deliberar sobre as destinações das receitas, recursos e demais rendas auferidas pelo Instituto.

Por sua vez, a diretoria executiva é composta por três membros: a superintendente geral, a diretora de previdência e a diretora de assistência. A superintendente geral representa a entidade, ativa e passivamente, em juízo ou fora dele, gerir e dirigir todas as atividades administrativas da entidade e seus recursos econômicos e financeiros. Além dessas atribuições, supervisiona as atividades das demais diretoras, colaborando na gestão. Por seu turno, as diretoras em suas respectivas áreas de atuação, sendo na previdência ou assistência, compete desincumbir-se das funções e atribuições cominadas, pertinentes às áreas de atuação correspondentes, colaborar com a superintendência geral, supervisionar as atividades e interesses do instituto, cumprir os atos regulamentares e as deliberações do conselho deliberativo.

O conselho fiscal, é incumbido de fiscalizar os atos dos Diretores e verificar o cumprimento de seus deveres legais e regulamentares, podem opinar a respeito dos orçamentos e balanços do instituto, examinam todas as contas, escrituração, documentos, registros contábeis e demais papeis do instituto. Quando solicitado, ou sempre que se faz necessário emitem pareceres sobre os resultados gerais do exercício e propostas orçamentarias. A contabilidade é um setor a parte do conselho fiscal, suas obrigações são demonstrar as receitas 
e despesas, da previdência, da assistência à saúde, da administração, e dos investimentos da entidade.

Os setores de assistência e conferência são por vezes confundidas ou até se tornam semelhantes. A assistência é o todo, engloba todos os assuntos de sua responsabilidade, já a conferência é uma divisão dentro da assistência. A assistência conta com a recepção, que atende diretamente os segurados. Na recepção são emitidas as autorizações, que ocorrem conforme a necessidade do servidor amparado pelo plano. A recepção tem a função de recolher as solicitações diversas para com a assistência, e repassá-las a respectiva responsável. O que ocorre também com os documentos da conferência, quando os mesmos chegam à recepção, como as contas a serem conferidas. Na Tabela 1, estão descritas as atividades da assistência e da conferência.

Tabela 1 - Atribuições da assistência e da conferência

\begin{tabular}{|c|c|}
\hline Atribuições da Assistência & Atribuições da Conferência \\
\hline Deliberações do conselho. & Verificação das contas médicas. \\
\hline Requerimentos dos servidores para com a assistência. & $\begin{array}{l}\text { Protocolização dos documentos que serão } \\
\text { conferidos ao longo do período. }\end{array}$ \\
\hline Liberações e agendamentos de procedimentos. & Arquivamento das contas conferidas. \\
\hline $\begin{array}{l}\text { Requisições dos descontos em folha referente à } \\
\text { coparticipação. }\end{array}$ & \\
\hline
\end{tabular}

Fonte: Elaborado pelos autores.

O setor de conferência realiza a verificação das contas médicas dos credenciados do instituto. Todos os documentos que resultam desta verificação são resguardados pela conferência. O setor possui dois servidores, a equipe auditora e o sistema da saúde. Os dois servidores, os entrevistados B e D, trabalham em turnos diferentes, a entrevistada B faz a carga horaria das $07 \mathrm{~h}$ às $13 \mathrm{~h}$, o servidor $\mathrm{D}$ realiza o turno das $12 \mathrm{~h} 30 \mathrm{~min}$ às $18 \mathrm{~h} 30 \mathrm{~min}$. A equipe auditora é contratada por contrato de serviço, sua carga horaria é estipulada em 20h semanais.

Os dados foram coletados por meio de entrevistas semiestruturadas, com questões abertas, a fim de entender a percepção dos entrevistados sobre o universo organizacional (Roesch, 2005). As entrevistas foram realizadas próximas ao dia 15 do mês de julho de 2019, sendo as mesmas gravadas e transcritas. O roteiro utilizado na entrevista, foi o seguinte:

- Quais são as atividades que são realizadas no setor de conferência?

- Quem faz cada tipo de atividade?

- Quanto tempo é necessário para realizar cada atividade?

- Qual a finalidade de cada atividade?

- Quantas pessoas atuam no setor?

- Que tipo de situações alteram as atividades no setor? 
- Quais ferramentas são utilizadas para controle das atividades?

- Quais são os problemas que acontecem?

- Quais são as regras que orientam o setor?

- O que pode ser aprimorado?

- Que tipo de mudanças são necessárias?

A Tabela 2 revela o perfil dos profissionais entrevistados do setor de conferência, unidade de análise desta pesquisa.

Tabela 2 - Identificação dos sujeitos da pesquisa

\begin{tabular}{|c|c|c|c|c|}
\hline Entrevistado & Cargo & Formação & $\begin{array}{l}\text { Tempo como } \\
\text { servidor }\end{array}$ & Tempo no setor \\
\hline $\mathrm{A}$ & $\begin{array}{l}\text { Diretora de } \\
\text { Assistência }\end{array}$ & $\begin{array}{l}\text { Tecnólogo em } \\
\text { Gestão Pública }\end{array}$ & $\begin{array}{l}\text { Desde agosto de } \\
2003\end{array}$ & Desde novembro de 2016 \\
\hline B & $\begin{array}{l}\text { Assistente } \\
\text { administrativo }\end{array}$ & $\begin{array}{l}\text { Tecnólogo em } \\
\text { Enfermagem }\end{array}$ & $\begin{array}{l}\text { Desde abril de } \\
2016\end{array}$ & Desde abril de 2018 \\
\hline $\mathrm{C}$ & $\begin{array}{l}\text { Assistente } \\
\text { administrativo }\end{array}$ & $\begin{array}{l}\text { Bacharel em } \\
\text { Administração }\end{array}$ & $\begin{array}{l}\text { Desde julho de } \\
2012\end{array}$ & Desde maio de 2014 \\
\hline $\mathrm{D}$ & $\begin{array}{l}\text { Encarregado do } \\
\text { setor de assistência }\end{array}$ & Ensino Médio & $\begin{array}{l}\text { Desde janeiro de } \\
2017\end{array}$ & Desde abril de 2018 \\
\hline
\end{tabular}

Fonte: Dados da pesquisa.

Dentre as aplicações para o estudo de caso citado por Yin (2015), procurou-se descrever o contexto da vida real e realizar uma avaliação descritiva. Além do mais, Yin (2015) sinaliza que um ponto muito importante da coleta de dados para um estudo de caso é a oportunidade de utilizar diversas fontes para a obtenção de evidências. Segundo o autor, a triangulação de dados permite cruzar informações obtidas por diferentes instrumentos de coletas de dados. No caso desta pesquisa, as fontes foram o resultado do referencial teórico, o conteúdo das quatro entrevistas e a observação participante, visto que um dos autores trabalha na unidade de análise.

Os dados foram analisados por meio da análise de conteúdo, proposta por Bardin (2011). Segundo a autora, este método consiste em procedimentos para levantar inferências válidas a partir do texto, buscando classificar palavras, frases, ou mesmo parágrafos em categorias de conteúdo. Ressalta-se que as categorias de foram criadas a posteriori, sendo elas: i) Análise das atividades no setor de conferência; e, ii) Ferramentas e métodos para executar a gestão por processos.

\section{Resultados obtidos e análise}

Nesta seção, serão apresentados os resultados da análise de conteúdo, com base nas categorias de análise elencadas anteriormente. 


\subsection{Análise das atividades no setor de conferência}

Conforme os entrevistados A, B e C as “despesas médicas dos segurados são conferidas e auditadas individualmente, após os credenciados entregarem no instituto.” A entrevistada B, lista as atividades como "recebimento de faturas, separação, conferência, cálculo dos gastos e fechamento.” Faz menção à recepção da autarquia, "a qual protocola as contas recebidas e encaminha para o setor de conferência." Após chegarem ao setor, as contas são divididas em internação, Pronto Atendimento, ambulatório e exames diversos, sendo que "internações e Pronto Atendimento ficam com a auditoria técnica, sendo finalizadas pelo setor de conferência, que garante que as cobranças sejam pagas conforme as tabelas de prestação de contas.”

De um modo geral, o setor possui dois grupos de atividades: o primeiro formado pelos auditores, que conferem se os procedimentos foram realizados e cobrados da forma correta. $\mathrm{O}$ segundo, formado por dois servidores que conferem as contas de consultório, laboratórios, entre outros. O que é facilmente visível é o volume de atividades, tanto para os dois servidores do quadro funcional como para a equipe técnica. Destacando a distribuição das tarefas do setor, realizadas pela entrevistada $\mathrm{B}$ e entrevistado $\mathrm{C}$, que como constatado, não há uma ordenação ou critério para iniciar as verificações das contas, o que contraria as recomendações de autores Hammer (2001), Wagner (2020) e Gonçalves (2000).

A Tabela 3 descreve a divisão das atividades que os dois servidores realizam na conferência.

Tabela 3- Descrição das divisões dos servidores

\begin{tabular}{|c|l|l|}
\hline Entrevistado & \multicolumn{1}{|c|}{ Tarefas } & \multicolumn{1}{c|}{ Descrição dos procedimentos } \\
\hline B & $\begin{array}{l}\text { Conferir contas de } \\
\text { pronto atendimento, } \\
\text { ambulatórios e } \\
\text { procedimentos mais } \\
\text { complexos. }\end{array}$ & $\begin{array}{l}\text { Colonoscopias, endoscopias diagnósticas, endoscopias cirúrgicas, } \\
\text { endoscopias peroral, hemoterapia, quimioterapia, radioterapia, } \\
\text { angiologia, cirurgia cardíaca, hemodinâmica cirurgia de cabeça e } \\
\text { pescoço, dermatologia, aparelho digestivo, procedimentos de } \\
\text { ginecologia e obstetrícia, microcirurgia reconstrutiva, neurocirurgia, } \\
\text { oftalmológicos, ororrinolaringologia, ortopedia e traumatologia, } \\
\text { cirurgia pediátrica, plástica, torácica, urologia e colo-proctologia. }\end{array}$ \\
\hline D & $\begin{array}{l}\text { Conferir contas de } \\
\text { exames, fisioterapias } \\
\text { exames e } \\
\text { procedimentos simples. }\end{array}$ & $\begin{array}{l}\text { Consultas eletivas das diversas áreas da medicina, ultrassonografias, } \\
\text { radiografias, tomografias, ressonâncias, fisioterapias, exames de } \\
\text { análise clínica e exames de oftalmologia. }\end{array}$ \\
\hline
\end{tabular}

Fonte: Dados da pesquisa.

Cumpre destacar que o instituto possui plano de classificação de cargos e funções para os funcionários públicos, conforme preconiza a lei 2.275 de abril de 2002. Além disto, a equipe técnica é contratada mediante licitação, em concordância com a lei 8.666/1993, que estabelece normas gerais sobre licitações e contratos administrativos pertinentes a obras, serviços, 
inclusive de publicidade, compras, alienações e locações no âmbito dos Poderes da União, dos Estados, do Distrito Federal e dos Municípios (Campo Bom, 2002; Brasil, 1993).

Para a entrevistada A o tempo que a conferência demanda para examinar as contas, são “em média 25 dias para hospitais e laboratórios; e, em média 20 dias para consultórios e outros." A entrevistada B, por seu turno, salienta que algumas contas demandam 1 a 2 horas, outras 2 ou 3 dias." Já a entrevistada C, especifica que "as consultas e exames de baixa complexidade são de simples conferência." Para as contas de procedimentos (contas de pronto atendimento, exames que necessitam de anestesias ou medicamentos e as internações) a servidora $C$ aponta que demandam bastante tempo, pois "os materiais e medicamentos são conferidos por unidade de utilização."

Em média passam pelo setor em torno de 40 credenciados, entre pessoas físicas e jurídicas. Para o pagamento das contas da assistência é feito memorando, sendo que as informações são inseridas pelo servidor D e a entrega para a tesouraria é realizada até o $10^{\circ}$ dia do mês subsequente. A Tabela 4 demonstra a divisão das atividades no setor, e quais são as especificações que as orientam. Foi possível constatar que a organização interna não segue os princípios de sequenciamento de tarefas, dentro do fluxo operacional mais adequado, conforme sugerem os autores Slack e Brandon-Jones (2018), Klun e Trkman (2018).

Tabela 4 - Descritivo das definições das atividades no setor

\begin{tabular}{|l|l|l|l|}
\hline Tipo de Conta & \multicolumn{1}{|c|}{ Caracterização } & \multicolumn{1}{c|}{ Critérios de conferência } & Quem realiza \\
\hline Consultas & $\begin{array}{l}\text { Ordem emitida pelo sistema } \\
\text { da saúde retorna para } \\
\text { conferência. }\end{array}$ & $\begin{array}{l}\text { Assinatura do segurado; Assinatura } \\
\text { do médico prestador do serviço; } \\
\text { conferência dos valores pagos. }\end{array}$ & Servidor D. \\
\hline Exames & $\begin{array}{l}\text { Ordem emitida pelo sistema } \\
\text { da saúde retorna para } \\
\text { conferência. }\end{array}$ & $\begin{array}{l}\text { Assinatura do segurado; solicitação } \\
\text { médica; laudo do exame; } \\
\text { conferência dos valores pagos. }\end{array}$ & Servidor D. \\
\hline Pronto Atendimento & $\begin{array}{l}\text { Atendimentos urgentes } \\
\text { realizados em hospitais. }\end{array}$ & $\begin{array}{l}\text { Assinatura do segurado; Assinatura } \\
\text { do médico; Relatório de gastos; } \\
\text { laudos anexados. }\end{array}$ & Servidor B. \\
\hline Ambulatório & $\begin{array}{l}\text { Ordem emitida pelo sistema } \\
\text { da saúde retorna para } \\
\text { conferência. }\end{array}$ & $\begin{array}{l}\text { Assinatura do segurado; Assinatura } \\
\text { do médico; Solicitação médica; } \\
\text { Relatório de gastos; laudos. }\end{array}$ & Servidor B. \\
\hline Internações & $\begin{array}{l}\text { Ordem emitida pelo sistema } \\
\text { da saúde retorna para } \\
\text { conferência. }\end{array}$ & $\begin{array}{l}\text { Assinatura do segurado; Assinatura } \\
\text { do médico; Solicitação médica; } \\
\text { Relatório de gastos; laudos. }\end{array}$ & $\begin{array}{l}\text { Auditoria } \\
\text { Técnica }\end{array}$ \\
\hline Fisioterapia & $\begin{array}{l}\text { Ordem emitida pelo sistema } \\
\text { da saúde retorna para } \\
\text { conferência. }\end{array}$ & $\begin{array}{l}\text { Assinatura do segurado; Assinatura } \\
\text { do médico; Solicitação médica; }\end{array}$ & Servidor D. \\
\hline Procedimentos & $\begin{array}{l}\text { Ordem emitida pelo sistema } \\
\text { da saúde retorna para } \\
\text { conferência. }\end{array}$ & $\begin{array}{l}\text { Assinatura do segurado; Assinatura } \\
\text { do médico; Solicitação médica; }\end{array}$ & Servidor D e B. \\
\hline
\end{tabular}

Fonte: Dados da pesquisa. 
Conforme evidenciado na Tabela 4, a divisão de tarefas para os dois servidores separase por grau de complexidade, sendo que as contas de maior complexidade são conferidas pela entrevistada $\mathrm{B}$, visto que a mesma possui formação técnica em enfermagem. O setor possui ainda serviços administrativos, como a cópia das glosas das contas, já que os hospitais precisam saber quais foram as inconformidades que as contas apresentaram, para que seja cobrado ou não como um recurso de reapresentação. Evidencia-se nestas circunstâncias a tradicional distribuição do serviço por funções que são exercidas pelos funcionários, o que conduz a uma gestão hierárquica, rígida, departamental e vertical (Baldam, Valle \& Rozenfeld, 2014).

Para efetuar a verificação das contas, o setor se orienta por uma planilha, sendo os valores reajustados e enviados por e-mail para os credenciados no mês de maio de cada ano. Outro documento gerado é a lista de espera para a realização dos procedimentos. A lista contém nome do segurado o exame ou procedimento que necessita realizar e a data do agendamento. Os dois servidores da conferência, também são responsáveis por levantar todos os documentos de prestação de contas de um espólio e incluir e excluir dependentes no sistema de assistência à saúde.

Quando abordada sobre quais regras orientam o funcionamento do setor, a entrevistada A assinala que "sempre procuramos orientar os colaboradores que existe uma tabela a ser seguida, e que temos auditores técnicos auxiliando." Segundo a entrevistada B, "nos baseamos pelo cronograma de datas do pagamento dos prestadores de serviço.” Já a entrevistada C, cita apenas o prazo de conferência. De acordo com o observado, o setor não possui definição clara das ordens que orientam o setor, conforme as contas chegam as mesmas são conferidas, mas acontecem pausas, seja para atender os segurados ou para arquivar as contas dos meses anteriores. Ressalta-se que o cronograma mencionado pela entrevistada B é uma informação de conhecimento dos servidores, pois refere-se a apenas uma data.

Referente as situações que alteram as atividades no setor, a entrevistada A menciona a “exoneração ou transferência de setor e falhas no sistema de saúde.” Para a entrevistada B, são os atrasos da equipe técnica, pois "demorar na conferência atrasa o fechamento", salientando a falta de nota fiscal nas contas, informações incompletas e utilização de códigos errados. A entrevistada $\mathrm{C}$, salienta a demora dos prestadores de serviço para o envio dos orçamentos e as demandas que chegam a caráter de urgência, divergências nos valores cobrados e pagos aos credenciados. Os entrevistados sinalizam "falhas e mau funcionamento do sistema, ocasionando perdas de dados".

Com relação as ferramentas utilizadas para controle das atividades, destaca-se o sistema que possui cadastro dos servidores e controle de gastos individual, contudo, todas as contas são 
físicas e arquivadas em caixas identificadas. As contas são armazenadas em caixas, em uma sala com prateleiras e ordenadas em ordem numérica de processo. As contas de um mês em média dão o volume de sete caixas de arquivo morto. Os documentos que o setor dispõe são obtidos no sistema DAS que disponibiliza relatórios com as quantidades de todos os procedimentos realizados. O sistema emite relatórios, por períodos e procedimento. Contudo, a conferência eletrônica poderia aperfeiçoar este processo visto que hoje é realizado manualmente.

\subsection{Ferramentas e métodos para executar a gestão por processos}

A partir da descrição das atividades do setor de conferência da Autarquia, é possível constatar a complexidade no conteúdo do trabalho exercido. Ademais, não é possível mensurar o tempo necessário para que cada conta seja conferida, pois acontecem requerimentos diversos, que os servidores precisam atender, ocasionando atrasos e distração dos servidores. Os processos são burocráticos, manuais e não possuem fluxograma das atividades, por vezes é confuso identificar quais etapas estão sendo realizadas, quais já foram e quais ainda não foram realizadas. Cumpre destacar que não foi encontrado nenhum instrumento que delimita os critérios para liberação das contas, e, tão pouco um documento que mantenha um histórico das adversidades encontradas.

Neste sentido, entende-se que a gestão por processos como ferramenta de gestão para a conferência preencheria as demandas do setor, visto que, segundo os autores Gonçalves (2000), Jesus e Macieira (2014) a gestão por processos resulta na melhoria contínua dos processos, amplia os níveis de eficiência atendendo às necessidades dos clientes, sejam internos ou externos. Neste contexto, os softwares de BPM auxiliariam na compreensão das informações no setor, visto que o único controle que o setor possui é a entrega do memorando no dia dez de cada mês. Segundo Chang (2016), através da BPM é possível enxergar as pessoas e suas funções, mapear todos os processos da empresa, estabelecer o fluxo de trabalho, acompanhar e medir suas rotinas, resultando melhores resultados do negócio como um todo.

Para executar a gestão por processos, os autores Gyory, Cagan e Kotovsky (2019) apontam etapas de transformação, sendo elas o mapeamento, modelagem, oportunidade de melhoria, implantação/padronização e monitoramento. Na conferência, tais etapas poderiam ser praticadas. A Tabela 5, demonstra as definições das etapas e sugestões para o setor em estudo. 
Tabela 5 - Etapas de transformação

\begin{tabular}{|l|l|l|l|l|}
\hline Mapeamento & Modelagem & $\begin{array}{l}\text { Oportunidade de } \\
\text { Melhoria }\end{array}$ & $\begin{array}{l}\text { Implantação/ } \\
\text { Padronização }\end{array}$ & Monitoramento \\
\hline $\begin{array}{l}\text { Anotações dos } \\
\text { servidores e } \\
\text { reuniões com } \\
\begin{array}{l}\text { integrantes do } \\
\text { setor. }\end{array}\end{array}$ & Fluxograma. & $\begin{array}{l}\text { A partir do fluxograma, } \\
\text { identificar os processos } \\
\text { que não são eficientes para } \\
\text { o setor. }\end{array}$ & $\begin{array}{l}\text { Identificar os } \\
\text { processos, } \\
\text { subprocessos, } \\
\text { tarefas, atividades } \\
\text { do setor. }\end{array}$ & Papel da direção. \\
\hline
\end{tabular}

Fonte: Elaborado com base em Gyory, Cagan e Kotovsky (2019).

Todas as etapas envolvem, em algum momento, todos os integrantes do setor, sendo assim, todos podem contribuir com informações das atividades que os mesmos realizam, visto que estas informações são fundamentais para a execução das etapas da gestão por processos. Mas como é natural, quando acontece uma mudança, é inevitável que ocorra desconforto nos elementos envolvidos, tal como sinalizado por Gonçalves (2000), que afirma que a gestão por processos traz desconforto nos colaboradores, por atribuir responsabilidade aos donos dos processos.

Por meio da ferramenta de gestão $B P M$ é possível enxergar as pessoas e suas funções, mapear todos os processos, estabelecer o fluxo de trabalho e acompanhar e medir suas rotinas. (Chang, 2016). A entrevistada A cita um sistema que poderia ter comunicação direta com o credenciado para que quando as contas chegassem ao instituto os valores já estivessem ajustados com os valores tabelados, a entrevistada B identifica a necessidade de informatização no setor. O sistema DAS que é próprio do instituto poderia possuir ferramentas compatíveis com a $B P M$ e ainda suprir as necessidades apontadas pelas entrevistadas. Esta modificação no sistema DAS poderia ocorrer por meio de contratação de profissionais com conhecimento técnico em softwares, uma vez que os servidores da conferência estão habituados com o sistema seria de fácil compreensão as novas ferramentas implementadas no mesmo.

\section{Considerações finais}

O objetivo desta pesquisa foi o de evidenciar as tarefas que integram o setor de conferência em uma Autarquia de previdência pública do município de Campo Bom, no estado do Rio Grande do Sul, com o objetivo de analisar a possibilidade da implementação da gestão por processos. A pesquisa facultou a identificação das ferramentas e métodos para executar a gestão por processos, a partir da evidenciação de falhas na gestão operacional que ocorrem no setor apontados pelos próprios funcionários, como os processos manuais que poderiam ser automatizados, burocracia e volume excessivo de papéis no setor, evidenciando a necessidade de alteração no funcionamento atual da conferência. A aplicação da gestão por processos no setor, possibilitará, em um primeiro momento, a visualização dos processos que ocorrem diariamente.

Cumpre destacar que, com o mapeamento dos processos confirmou-se a viabilidade de adoção da gestão por processos no setor analisado, bem como os potenciais benefícios para os 
servidores envolvidos, tais como a redução de ocorrência de erros e retrabalho, ocasionando maior agilidade na execução das tarefas. Tais achados, também caracterizam as principais contribuições do estudo, no que diz respeito às características práticas e gerenciais na implementação da gestão por processos.

Embora cuidados metodológicos tenham sido tomados, como limitação da pesquisa, ressalta-se a descrição das atividades da conferência em virtude da complexidade nos termos e simbolismo presentes no setor da saúde. Para futuras pesquisas propõe-se estudos direcionados a abordagem de ferramentas gerenciais e administrativas de tecnologia da informação aplicados a administração pública.

\section{Referências}

Araujo, R. M., \& Magdaleno, A. M. (2015). Social BPM: Processos de Negócio, Colaboração e Tecnologia Social.

Baldam, R., Valle, R., \& Rozenfeld, H. (2014). Gerenciamento de Processos de Negócio BPM: uma referência para implantação prática.

Barbará, S. (2008). Gestão por processos: fundamentos, técnicas e modelos de implementação: foco no sistema de gestão da qualidade com base na ISO 9000: 2000. Qualitymark Editora Ltda.

Bardin, L. (2011). Análise de Conteúdo/Laurence Bardin; Tradução Luís Antero Reto, Augusto Pinheiro. São Paulo: Edições, 70.

Bergue, S. T. (2010). Gestão de pessoas em organizações públicas. In Gestão de pessoas em organizações públicas (pp. 599-599). Caxias do Sul; EDUCS; 3 ed

Biazzi, M., \& Muscat, A. R. N. (2007). Modelo de aperfeiçoamento de processos administrativos para instituições públicas de ensino superior brasileiras. Encontro da Associação Nacional de Pós-Graduação em Administração, Rio de Janeiro. Anais Enanpad.

Brasil. Lei n ${ }^{0}$ 8.666, de 21 de junho de 1993. Regulamenta o art. 37, inciso XXI, da Constituição Federal, institui normas para licitações e contratos da Administração Pública e dá outras providências. Disponível em: http://www.planalto.gov.br/ccivil_03/leis/18666cons.htm. Acesso em: 30 abr 2020.

Brocke, V. J., \& Rosemann, M. (2013). Manual de BPM: gestão de processos de negócio. Bookman editora.

Campo Bom. Lei No 2275, DE 09/04/2002. Institui o Plano de Classificação de Cargos e Funções do Instituto de Previdência e Assistência dos Servidores Municipais de Campo Bom - IPASEM, e dá Outras Providências. Disponível em: https://leismunicipais.com.br/a1/rs/c/campo-bom/lei-ordinaria/2002/227/2275/lei-ordinaria- 
n-2275-2002-institui-o-plano-de-classificacao-de-cargos-e-funcoes-do-instituto-deprevidencia-e-assistencia-dos-servidores-municipais-de-campo-bom-ipasem-e-da-outrasprovidencias. Acesso em: 30 abr 2020.

Chang, J. F. (2016). Business process management systems: strategy and implementation. CRC Press.

Contador, J. C., De Sordi, J. O., de Lourdes Marinho, B., \& de Carvalho, M. F. H. (2005). Gestão do conhecimento aplicada à gestão por processos: Identificação de funcionalidades requeridas às soluções de Business Process Management System (BPMS). RAI-Revista de Administração e Inovação, 2(2), 5-18.

De Sordi, J. O. (2017). Gestão por processos. Editora Saraiva.

Ferreira, V. C., Silveira, M. C., Oliveira, K. P., \& Moraes, C. E. S. (2014). Contribuições do gerenciamento de processos para a administração pública mineira. Reuna, 19(1), 5-28.

Gespública, Governo Federal. (2010). Programa Nacional de Gestão Pública e Desburocratização. Guia de gestão de processos do Governo.

Gespública, Governo Federal. (2016). Programa Nacional de Gestão Pública e Desburocratização. Instrumento para Autoavaliação da Gestão Pública - Guia Prático de Aplicação. Brasília; MP, SEGEP.

Gonçalves, J. E. L. (2000). As empresas são grandes coleções de processos. Revista de administração de empresas, 40(1), 6-9.

Gulledge, T. R., \& Sommer, R. A. (2002). Business process management: public sector implications. Business Process Management Journal. 8 (4), 364-376.

Gyory, J. T., Cagan, J., \& Kotovsky, K. (2019). Are you better off alone? Mitigating the underperformance of engineering teams during conceptual design through adaptive process management. Research in Engineering Design, 30(1), 85-102.

Hammer, M. (2001). A agenda: o que as empresas precisam fazer para dominar esta década. Rio de Janeiro: Campus.

Harmon, P. (2019). Business process change: a business process management guide for managers and process professionals. Morgan Kaufmann.

Klun, M., \& Trkman, P. (2018). Business process management-at the crossroads. Business Process Management Journal, 24(3), 786-813.

Pavani Junior, O., \& Scucuglia, R. (2011). Mapeamento e gestão por processos-BPM. São Paulo: M. Books.

Roesch, S. M. A. (2005). Projetos de estágio e de pesquisa em administração: Guia para estágios, trabalhos de conclusão, dissertações e estudos de caso. 3. ed. São Paulo, SP: Atlas. 
Slack, N., \& Brandon-Jones, A. (2018). Operations and process management: principles and practice for strategic impact. Pearson UK.

Wagner, J. (2020). Comportamento organizacional. Saraiva Educação SA.

Yin, R. K. (2015). Estudo de Caso-: Planejamento e Métodos. Bookman editora. 